\title{
IRIS RETRACTOR FOR USE WITH CRYOEXTRACTORS*†
}

BY

\author{
M. M. S. DU TOIT \\ Calgary, Alberta, Canada
}

Cryoextraction has been established as a safe, indeed the safest, method of removing the cataractous lens. Numerous instruments have been designed for this purpose.

Certain problems tend to present during this operation, in spite of careful attention to the preparation:

(a) Even when the pupil is widely dilated at the start of the operation, it tends to become smaller during the opening of the eye and the performance of the iridectomy.

(b) The problem of the tight pupil that shows a minimal response to the instillation of mydriatics is virtually insurmountable.

(c) The use of intra-cameral mydriatics at the time of the operation causes an unavoidable and annoying delay.

(d) Performing a full iridectomy does not reduce the danger of adhesion of the iris to the extractor tip.

The only complete solution to these problems is the use of an adequate and suitable iris retractor. It is the purpose of this paper to describe such an instrument.

The instrument (Figure) has a right-hand blade at one end of the handle and a left-hand blade at the other end. Each blade has a flat scleral flange and a retractor blade, the concavity of which conforms to that of the scleral lip of the corneo-scleral wound. The width of the blade is about $6 \mathrm{~mm}$. chord of arc, providing a suitably wide area for manipulation of the extractor while keeping the iris safely out of the way.

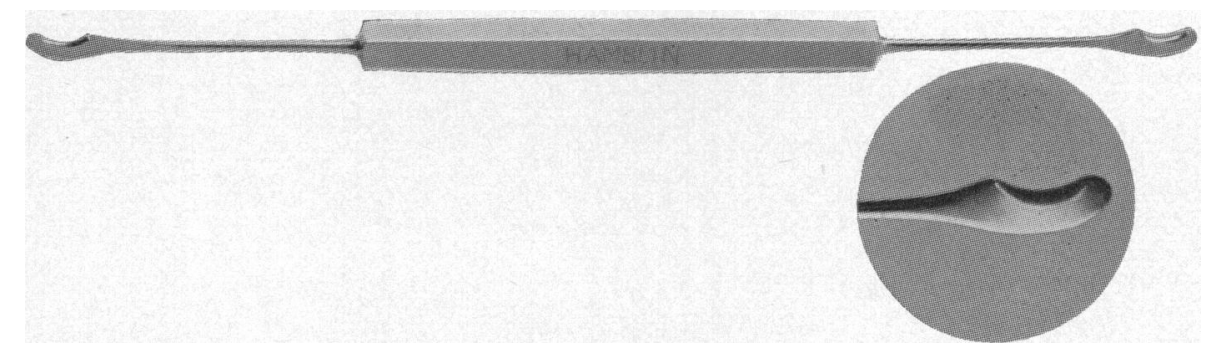

FIGURE.-Iris retractor with blades at each end.

* Received for publication July 19,1966

† Address for reprints: Johnson Eye Clinic, 8th Avenue and 8th Street, S.W., Calgary, Alberta, Canada. 


\section{Method of Use}

The retractor can be used only if a round-pupil extraction is done. Once everything is in readiness for the extraction, the iris is grasped by means of iris forceps at or close to the pupillary margin, and lifted up and towards the 12 o'clock position. The iris retractor, held at the side of the patient's head, is introduced in sliding fashion, making quite certain that the iris fits securely into the hollow of the blade, and is then moved upwards to engage the scleral lip of the wound. The retractor can be held by the surgeon or his assistant, and will leave the area above free for the surgeon's manipulations.

\section{Summary}

An iris retractor, with right and left hand blades, has been designed for use with cryoextractors. The instrument is held at the side of the patient's head, leaving the area above free for the surgeon. The width of the blade ensures that the iris is held well out of harm's way, virtually eliminating the possibility of entangling the iris with the extractor tip.

My thanks are due to Messrs. Paul Hamblin and Alan Snook of Hamblins Ltd., for their patient cooperation in the development phase of this instrument; to Mr. L. G. Fison, for helpful criticism, encouragement, and actual trial of the instrument; and to Mr. G. T. W. Cashell for encouragement. 